\title{
P I 0-0 I. MHC class I chain-related protein A shedding in chronic HIV-I infection is associated with profound NK cell dysfunction
} A Nolting*1, R Luteijn ${ }^{1}$, A Dugast ${ }^{1}$, M Carrington ${ }^{1}$, S Rihn ${ }^{1}$, K Kane ${ }^{1}$, S Jost ${ }^{1}$, I Toth ${ }^{1}$, G Faetkenheuer ${ }^{2}$, P Hartmann ${ }^{2}$, M Altfeld ${ }^{1}$ and G Alter ${ }^{1}$

\author{
Address: ${ }^{1}$ AIDS, Innate Immunity, Ragon Institute of MGH, Harvard, MIT (Boston, MA), Charlestown, USA and ${ }^{2}$ Infectious Diseases Department \\ of the University Hospital of Cologne, Cologne, Germany \\ * Corresponding author
}

from AIDS Vaccine 2009

Paris, France. 19-22 October 2009

Published: 22 October 2009

Retrovirology 2009, 6(Suppl 3):PI32 doi:I0.II86/I742-4690-6-S3-PI32

This abstract is available from: http://www.retrovirology.com/content/6/S3/PI32

(c) 2009 Nolting et al; licensee BioMed Central Ltd.

\section{Background}

Natural killer (NK) cells play a critical role in the host defense against viral infections. However, chronic HIV-1 infection is associated with an accumulation of dysfunctional NK cells that poorly control viral replication. The underlying mechanism for this NK cell mediated dysfunction is not well understood. Certain tumors directly evade NK cell mediated detection by dampening NK cell activity via the downregulation of NKG2D, a potent activating NK cell receptor, via the release of soluble NKG2D-ligands. This results in a potent suppression of NK cell function. We hypothesized that NKG2D-mediated cytotoxicity in chronic HIV-1 infection is impaired and associated with shedding of NKG2D ligand MICA (sMICA).

\section{Methods}

Flow cytometric analysis was performed on 100 subjects to quantify NKG2D expression and NK cell functional responses (cell activation (CD69) and degranulation (CD107a)) following stimulation with K562 (MHCdevoid, NKG2D target) and 221 cells (MHC devoid, nonNKG2D target). Additionally, the level of MICA and matrix metalloproteases (MMP, involved in NKG2D-ligand shedding) were quantified by quantitative PCR. Finally, the level of secreted MICA was measured by ELISA.

\section{Results}

Here we show for the first time that chronic HIV-1 infection is associated with a specific defect in NKG2D-mediated activation of NK cells, due to alterations in both the expression and transcription of NKG2D in NK cells. Reduced NKG2D expression was associated with elevated levels of the NKG2D-ligand, MICA, in patient sera, likely released by HIV infected CD4+ T cells due to enhanced enzymatic cleavage, by MMPs, of this stress inducible molecule from the surface of the target cell.

\section{Conclusion}

Thus, HIV is able to indirectly suppress NK cell mediated functional recognition of HIV-infected CD4+ T cells by enhancing NKG2D-ligand secretion into the peripheral circulation resulting in a profound impairment of NK cell function. 